\title{
Benfotiamine increases glucose oxidation and downregulates NADPH oxidase 4 expression in cultured human myotubes exposed to both normal and high glucose concentrations
}

\author{
D. A. Fraser • N. P. Hessvik • N. Nikolić • \\ V. Aas - K. F. Hanssen - S. K. Bøhn • \\ G. H. Thoresen - A. C. Rustan
}

Received: 16 May 2011/ Accepted: 23 September 2011/Published online: 9 October 2011

(C) Springer-Verlag 2011

\begin{abstract}
The aim of the present work was to study the effects of benfotiamine (S-benzoylthiamine O-monophosphate) on glucose and lipid metabolism and gene expression in differentiated human skeletal muscle cells (myotubes) incubated for 4 days under normal $(5.5 \mathrm{mM}$ glucose) and hyperglycemic (20 $\mathrm{mM}$ glucose) conditions. Myotubes established from lean, healthy volunteers were treated with benfotiamine for 4 days. Glucose and lipid metabolism were studied with labeled precursors. Gene expression was measured using real-time polymerase chain reaction (qPCR) and microarray technology. Benfotiamine significantly increased glucose oxidation under normoglycemic (35 and $49 \%$ increase at 100 and $200 \mu \mathrm{M}$ benfotiamine, respectively) as well as hyperglycemic conditions
\end{abstract}

Electronic supplementary material The online version of this article (doi:10.1007/s12263-011-0252-8) contains supplementary material, which is available to authorized users.

\section{A. Fraser}

Diabetes Research Centre,

Oslo University Hospital, Oslo, Norway

N. P. Hessvik · N. Nikolić · G. H. Thoresen · A. C. Rustan ( $\square)$ Department of Pharmaceutical Biosciences, School of Pharmacy, University of Oslo, Oslo, Norway

e-mail: arild.rustan@farmasi.uio.no

\section{Aas}

Faculty of Health Sciences,

Oslo University College, Oslo, Norway

K. F. Hanssen

Department of Endocrinology,

Oslo University Hospital, Oslo, Norway

S. K. Bøhn

Department of Nutrition, Faculty of Medicine, Institute of Basic

Medical Sciences, University of Oslo, Oslo, Norway
(70\% increase at $200 \mu \mathrm{M}$ benfotiamine). Benfotiamine also increased glucose uptake. In comparison, thiamine $(200 \mu \mathrm{M})$ increased overall glucose metabolism but did not change glucose oxidation. In contrast to glucose, mitochondrial lipid oxidation and overall lipid metabolism were unchanged by benfotiamine. The expression of NADPH oxidase 4 (NOX4) was significantly downregulated by benfotiamine treatment under both normo- and hyperglycemic conditions. Gene set enrichment analysis (GSEA) showed that befotiamine increased peroxisomal lipid oxidation and organelle (mitochondrial) membrane function. In conclusion, benfotiamine increases mitochondrial glucose oxidation in myotubes and downregulates NOX4 expression. These findings may be of relevance to type 2 diabetes where reversal of reduced glucose oxidation and mitochondrial capacity is a desirable goal.

Keywords Benfotiamine - Thiamine Myotubes · Diabetes · Hyperglycemia

\begin{tabular}{|c|c|}
\hline \multicolumn{2}{|c|}{ Abbreviations } \\
\hline NAD & Nicotinamide adenine dinucleotide \\
\hline NADPH & Nicotinamide adenine dinucleotide phosphate \\
\hline NOX & $\begin{array}{l}\text { Nicotinamide adenine dinucleotide phosphate } \\
\text { oxidase }\end{array}$ \\
\hline TK & Transketolase \\
\hline PPP & Pentose phosphate pathway \\
\hline PDH & Pyruvate dehydrogenase \\
\hline $\mathrm{KDH}$ & Ketoglutarate dehydrogenase \\
\hline TCA & Tricarboxylic acid \\
\hline IMTG & Intramyocellular triacylglycerol \\
\hline SPA & Scintillation proximity assay \\
\hline NG & Normoglycemic \\
\hline HG & Hyperglycemic \\
\hline MDK & Growth factor midkine \\
\hline
\end{tabular}


TMP Thiamine monophosphate

TPP Thiamine diphosphate

RFC Reduced folate carrier

OXPHOS Oxidative phosphorylation metabolic fate of labeled glucose and fatty acids under conditions of normal glucose $(5.5 \mathrm{mM})$ or chronic hyperglycemia (20 mM glucose) for 4 days. To assess whether metabolic changes were associated with changes in gene expression, we also isolated RNA and measured gene expression using real-time polymerase chain reaction (qPCR) and human gene expression microarrays.

\section{Materials and methods}

Chronic hyperglycemia plays a major role in the development of vascular complications associated with both type 1 and 2 diabetes (UK Prospective Diabetes Study (UKPDS) Group 1998; Brinchmann-Hansen et al. 1992; The Diabetes Control and Complications Trial Research Group 1993). These effects are believed to occur secondary to a buildup of glucose and glycolytic intermediates in the cytosol during bouts of hyperglycemia when intracellular glucose concentrations are abnormally increased (Brownlee 2001). Benfotiamine, a synthetic thiamine monophosphate analogue with improved intestinal absorption as compared with thiamine, prevents the adverse cellular changes associated with hyperglycemia and can prevent the development of diabetic retinopathy in mice (Balakumar et al. 2010; Hammes et al. 2003). These effects are believed to be mediated by increasing the activity of thiamine-dependent and rate-limiting enzyme of the pentose phosphate pathway (PPP), transketolase (TK), which shifts excess glycolytic metabolites away from central biochemical pathways of hyperglycemic damage (Hammes et al. 2003). It has also been shown that benfotiamine functions as a direct antioxidant in rodents, which may contribute to its beneficial effect (Schmid et al. 2008).

In addition to the harmful effects on the vasculature, hyperglycemia also contributes to insulin resistance in skeletal muscle (Richter et al. 1988). We have previously shown that myotubes exposed to chronic hyperglycemia have increased lipogenesis and intramyocellular triacylglycerol (IMTG) accumulation (Aas et al. 2004). The mechanisms by which these effects occur are complex and remain unknown but might involve mitochondrial dysfunction (Aas et al. 2011). It has been suggested that mitochondrial dysfunction is integral in the pathophysiology of insulin resistance and that its reversal may prevent the development of a number of metabolic sequelae associated with type 2 diabetes (Pagel-Langenickel et al. 2010).

Oral benfotiamine results in a 10-40\% increased incorporation of thiamine into liver and heart, whereas the incorporation is 5- to 25-fold higher into muscle and brain (Hilbig and Rahmann 1998). To improve our understanding of how benfotiamine affects glucose and lipid metabolism in cultured human skeletal muscle cells, we have therefore studied the effects of benfotiamine on the
Dulbecco's Modified Eagle's Medium low glucose (DMEM), L-glutamine, penicillin/streptomycin (10,000 IE/ $10 \mathrm{mg} / \mathrm{ml}$ ), HEPES, amphotericin B and L-carnitine were from Sigma-Aldrich, St. Louis, MO, US. Foetal calf serum (FCS), Dulbecco's Phosphate Buffered Saline (DPBS) and trypsin/EDTA $(0.05 \%)$ were from Gibco/Invitrogen, Grand Island, NY, USA. Ultroser G was from Pall Corporation, St-Germain-en-Laye Cedex, France. D- $\left[1-{ }^{14} \mathrm{C}\right]$ glucose $(54 \mathrm{mCi} / \mathrm{mmol}), \quad\left[{ }^{14} \mathrm{C}\right]$ deoxy-D-glucose $\quad(287 \mathrm{mCi} / \mathrm{mmol})$ and $\left[1-{ }^{14} \mathrm{C}\right]$ oleic acid $(53 \mathrm{mCi} / \mathrm{mmol})$ were purchased from PerkinElmer, NEN, Boston, MA, USA. D- $\left[{ }^{14} \mathrm{C}(\mathrm{U})\right]$ glucose $(5 \mathrm{mCi} / \mathrm{mmol})$ was provided by American Radiolabeled Chemicals Inc., St. Louis, MO, USA. Insulin Actrapid ${ }^{\circledR}$ was from Novo Nordisk, Bagsvaerd, Denmark. Corning ${ }^{\circledR}$ CellBIND ${ }^{\circledR}$ microplates were from Corning B.V. Life Sciences, Schipol-Rijk, the Netherlands, 96-well UNIFILTER $^{\circledR}$ microplate from Whatman, Middlesex, UK, and 96-well Isoplate, ScintiPlate ${ }^{\circledR}-96$ TC micoplates, and the scintillation liquid Optiphase Supermix was from Perkin Elmer, Waltham, Massachusetts, USA. Bio-Rad Protein Assay Dye Reagent was from Bio-Rad Laboratories, NY, USA. Agilent Total RNA isolation kit was obtained from Agilent Technologies (Santa Clara, CA, USA). Illumina Human-6 Express BeadChips version 3 arrays were from Illumina (San Diego, CA, USA).

\section{Human skeletal muscle cell cultures}

Satellite cells were isolated from the M. obliquus internus abdominis of 6 healthy donors, age $38.8( \pm 3.8)$ years, body mass index $22.1( \pm 1.5) \mathrm{kg} / \mathrm{m}^{2}$, fasting glucose $5.0( \pm 0.1)$ $\mathrm{mM}$, insulin, plasma lipids and blood pressure within normal range and no family history of diabetes. The biopsies were obtained with informed consent and approval by the Regional Committee for Research Ethics, Oslo, Norway. The cells were cultured in DMEM $(5.5 \mathrm{mM}$ glucose) with 2\% FCS, 2\% Ultroser G, L-glutamine $(4 \mathrm{mM})$, penicillin/streptomycin $(\mathrm{P} / \mathrm{S})$ and amphotericin $\mathrm{B}$ until $70-80 \%$ confluent. Myoblast differentiation to myotubes was then induced by changing medium to DMEM (5.5 mM glucose) with $2 \%$ FCS, 25 pM insulin, L-glutamine $(4 \mathrm{mM}), \mathrm{P} / \mathrm{S}$ and amphotericin B. Experiments were 
performed after 8 days of differentiation, and preincubation with benfotiamine (100-200 $\mu \mathrm{M})$ and/or hyperglycemia (20 mM glucose) was started after 4 days.

\section{Substrate oxidation assay}

The muscle cells were cultured on 96-well CellBIND ${ }^{\circledR}$ microplates. Substrate, $\left[\mathrm{U}_{-}{ }^{14} \mathrm{C}\right]$ glucose $(1 \mu \mathrm{Ci} / \mathrm{ml}, 200 \mu \mathrm{M})$ or $\left[1-{ }^{14} \mathrm{C}\right]$ oleic acid $(1 \mu \mathrm{Ci} / \mathrm{ml}, 100 \mu \mathrm{M})$ was given in DPBS with $10 \mathrm{mM}$ HEPES ( $1 \mathrm{mM}$ L-carnitine was also added with oleic acid as described previously (Aas et al. 2011)). A 96-well UNIFILTER ${ }^{\circledR}$ microplate was mounted on top of the CellBIND ${ }^{\circledR}$ plate as described before (Wensaas et al. 2007), and the cells were incubated at $37^{\circ} \mathrm{C}$ for $4 \mathrm{~h}$. The $\mathrm{CO}_{2}$ trapped in the filter was counted by liquid scintillation (MicroBeta ${ }^{\circledR}$, PerkinElmer). The remaining cell-associated radioactivity was also assessed by liquid scintillation, and the sum of $\mathrm{CO}_{2}$ and cell-associated radioactivity was considered as total substrate utilization. Protein content in each well was determined (Bradford 1976), and the data are presented as $\mathrm{CO}_{2} / \mathrm{mg}$ protein or cell-associated radioactivity/mg protein.

\section{Scintillation proximity assay}

Radiolabeled substrates taken up and accumulated by adherent cells were measured by scintillation proximity assay (SPA). The cells were grown and differentiated in 96-well ScintiPlate ${ }^{\circledR}-96$ TC SPA plates. Measurements of $\left[{ }^{14} \mathrm{C}\right]$ deoxyglucose $(1 \mu \mathrm{Ci} / \mathrm{ml})$ uptake by SPA were taken in DMEM without phenol red (Sigma, MO, cat. no. D5030) with additional $100 \mu \mathrm{M}$ glucose. Finally, the cells were washed 3 times with PBS and harvested with $0.1 \mathrm{M} \mathrm{NaOH}$ (200 $\mu \mathrm{l} /$ well). Protein was determined according to Bradford et al. (Bradford 1976).

\section{RNA isolation and microarray analysis}

Total RNA was prepared from primary myotubes from three donors using Agilent Total RNA isolation kit according to the supplier's protocol (Agilent Technologies). RNA was used individually, and RNA integrity was checked on chip analysis (Agilent 2100 bioanalyzer, Agilent Technologies, Santa Clara, CA, USA) according to the manufacturer's instructions. RNA was judged as suitable for array hybridization only if samples exhibited intact bands corresponding to the $18 \mathrm{~S}$ and $28 \mathrm{~S}$ ribosomal RNA subunits and displayed no chromosomal peaks or RNA degradation products (RNA Integrity Number $>9.0$ ). cRNA synthesis was performed using Illumina TotalPrep RNA Amplification (San Diego, CA, USA) according to the supplier's protocol. Hybridization, washing and scanning of Illumina Human-6 Express BeadChips version 3 arrays (San Diego, CA, USA) were according to standard Illumina protocols. Data extraction and quality control were performed using BeadStudio version 3.1.3.0 (Illumina) and the Gene Expression module 3.2.7. Arrays were normalized using quantile normalization, and expression estimates were calculated by GC robust multiarray average background adjustment. Gene set enrichment analysis (GSEA; Subramanian et al. 2005) was used to test the specific hypothesis that groups of genes involved in glucose metabolism were changed during benfotiamine treatment. Collections of gene sets were obtained using a gene set browser from the Broad Institute website http://www.broad.mit.edu/gsea/ (Molecular Signatures Database v3.0). This browser searches a number of publicly available sources (e.g., Biocarta, Kegg) where genes are grouped if they belong to the same pathway and share ontology terms or clinical phenotypes. Thus, it is possible to define specific gene sets on the basis of a particular parameter of interest. Similar use of GSEA has been published earlier (Bohn et al. 2010). Gene set collections relevant to glucose and energy metabolism were obtained using the following keywords stepwise: "glucose," "insulin," "energy," "lactate," "mitochondria," "transporter*" (*indicates truncated search), "lipid," "DNA and Repair" and "interleukin." The larger, predefined gene set collections: C2, C3TFT and C5 from http://www.broad. mit.edu/gsea/ were also tested. The C3 TFT (transcription factor targets) collection consists of gene sets that contain genes sharing a transcription factor-binding site defined in the TRANSFAC (version 7.4, http://www.gene-regulation. com/). The gene sets in the $\mathrm{C} 5$ collection are grouped according to the gene ontology consortium. The $\mathrm{C} 2$ gene sets are collected from various sources such as online pathway databases, publications in PubMed and knowledge of domain experts. The benfotiamine-treated samples were compared with untreated in paired GSEA analysis. GSEA was performed using J-express 2011 (http://www.molmine. com) according to the description on the J-express manual. The gene matrix was collapsed by selecting the maximum probes. Log-fold change was used as the scoring method, the number of permutations was set to 1,000 and gene sets with less than 10 genes or more than 500 genes were excluded from the analysis. False discovery rate (FDR) $q$ values $<5 \%$ were used as criteria for significantly enriched gene sets. Minimum Information About a Microarray Experiment (MIAME) standards (Brazma et al. 2001) were followed in the analysis and storage of microarray data. The raw data are available at the gene expression omnibus (GEO) at http://www.ncbi.nlm.nih.gov/geo/by accession number GSE31553. 
RNA isolation and analysis of gene expression by $\mathrm{TaqMan}^{\circledR} \mathrm{qPCR}$

Cells were harvested, and total RNA was isolated by Agilent Total RNA isolation kit (Agilent Technologies, Santa Clara, CA, USA) according to the supplier's total RNA isolation protocol. Total RNA was reverse-transcribed with oligo primers using a Perkin-Elmer Thermal Cycler $9600\left(25^{\circ} \mathrm{C}\right.$ for $10 \mathrm{~min}, 37^{\circ} \mathrm{C}$ for $1 \mathrm{~h} 20 \mathrm{~min}$ and $85^{\circ} \mathrm{C}$ for $5 \mathrm{~s}$ ) and a TaqMan reverse transcription reagent kit (High Capacity cDNA Reverse Transcription Kit, Applied Biosystems, USA). Two micrograms of total RNA was added per $20 \mu \mathrm{L}$ of total TaqMan reaction solution. Real-time PCR was performed using an ABI PRISMT 7000 Detection System (Applied Biosystems, USA). RNA expression was determined by SYBRT Green, and primers were designed using Primer ExpressT (Applied Biosystems, USA). Each target gene was quantified in triplicate and carried out in a $25 \mu \mathrm{L}$ reaction volume according to the supplier's protocol. All assays were run for 40 cycles $\left(95^{\circ} \mathrm{C}\right.$ for $12 \mathrm{~s}$ followed by $60^{\circ} \mathrm{C}$ for $60 \mathrm{~s}$ ). The housekeeping control genes GAPDH (FC $-1.1, P=0.8$ from microarray) and $36 \mathrm{~B} 4$ were both measured, and transcription levels are presented as averaged change relative to levels of GAPDH and 36B4. Primer sequences: GAPDH (acc.no. NM_008084): F: CAT GGCCTTCCGTGTTCCT, R: TGATGTCATCATACTTG GCAGGTT; 36B4 (acc.no. NM_007475): F: ATCTCCAG AGGCACCATTGAA, R: TCGCTGGCTCCCACCTT; NOX4 (acc.no. NM_016931): F: TGGACCTTTGTGCCT GTACTGT; R: TGAGGATGACTTATGACCGAAA.

\section{Statistics}

All data are presented as mean \pm SEM. Statistical comparison between different treatments was performed by linear mixed model (LMM) and ANOVA repeated measures using SPSS ver. 17.0 (SPSS Inc., Chicago, IL, USA). The parameter of interest was entered as the dependent variable, and pretreatment (with and without benfotiamine) and acute treatments were entered as fixed variables. Differences were considered statistically significant at $P$ values less than 0.05. All experiments were performed with at least triplicate observations, and replicate experiments were performed on cells from different donors. For microarray analysis, individual fold change (FC) for each donor was calculated by dividing the expression level after benfotiamine treatment on the expression level after control treatment. The individual fold change was then $\log 2$ transformed. Mean fold changes were calculated based on the $\log 2$-transformed individual fold changes, followed by the identification of differentially expressed probe sets using intensity-based moderated t-statistics (Sartor et al. 2006). $P$ values were corrected for multiple testing using
Benjamini and Hochberg's false discovery rate (FDR) method (Benjamini and Hochberg 1995). Probe sets that satisfied the criterion of FDR $<10 \%(q$ value $<0.1)$ and fold change $>1.5$ or $<-1.5$ were considered to be significantly regulated.

\section{Results}

Effects of incubation with benfotiamine on glucose metabolism

Under normoglycemic conditions ( $\mathrm{NG}, 5.5 \mathrm{mM}$ glucose), basal [ $\left.\mathrm{U}_{-}{ }^{14} \mathrm{C}\right]$ glucose oxidation $\left(\mathrm{CO}_{2}\right.$ formation) was significantly increased in myotubes after incubation with benfotiamine (increased by $35[P=0.02]$ and $49 \%[P=0.003]$, after 100 and $200 \mu \mathrm{M}$ benfotiamine for 4 days, respectively; Fig. 1a). We also measured glucose oxidation after incubation with lower concentrations of benfotiamine (1 and $10 \mu \mathrm{M})$ without observing any effect (Fig. 1d). Under hyperglycemic conditions (HG, $20 \mathrm{mM}$ glucose for 4 days), glucose oxidation was significantly increased by $70 \%$ after exposure to $200 \mu \mathrm{M}$ benfotiamine $(P=0.01$; Fig. 1a). Total metabolized glucose (sum of $\mathrm{CO}_{2}$ formation and cell-associated glucose) was also significantly increased for $200 \mu \mathrm{M}$ benfotiamine $(P=0.001$; Fig. 1b) under NG conditions. Accordingly, we found a significant increase in fractional oxidation of [U- ${ }^{14} \mathrm{C}$ ]glucose $\left(\mathrm{CO}_{2}\right.$ /sum of cell-associated plus $\left.\mathrm{CO}_{2}\right)$ after benfotiamine treatment $(100$ and $200 \mu \mathrm{M})$ under both normoglycemic and hyperglycemic conditions (Fig. 1c). We found no significant changes in glycogen synthesis after incubation with benfotiamine (data not shown). Hyperglycemia decreased both glucose oxidation and total metabolized glucose (Fig. 1a, b) in agreement with earlier observations (Aas et al. 2011).

The effect of benfotiamine on glucose metabolism was compared with thiamine. As shown in Fig. 2, both benfotiamine and thiamine increased total metabolized glucose at the highest concentration examined $(200 \mu \mathrm{M}$ for 4 days), although the effect of benfotiamine was greater than for thiamine, 64 and 19\%, respectively. There was no effect of thiamine on glucose oxidation (data not shown).

To assess whether the increase in glucose utilization was accompanied by an increase in glucose uptake, we measured cellular $\left[{ }^{14} \mathrm{C}\right]$ deoxyglucose uptake after incubation with benfotiamine. We found a small (17\%) increase $(P<0.001$ overall effect $)$ in glucose uptake after benfotiamine incubation for 4 days under NG conditions (Fig. 3).

Effects of benfotiamine on fatty acid metabolism

In contrast to the marked effects of benfotiamine on glucose metabolism, benfotiamine had no significant effects 

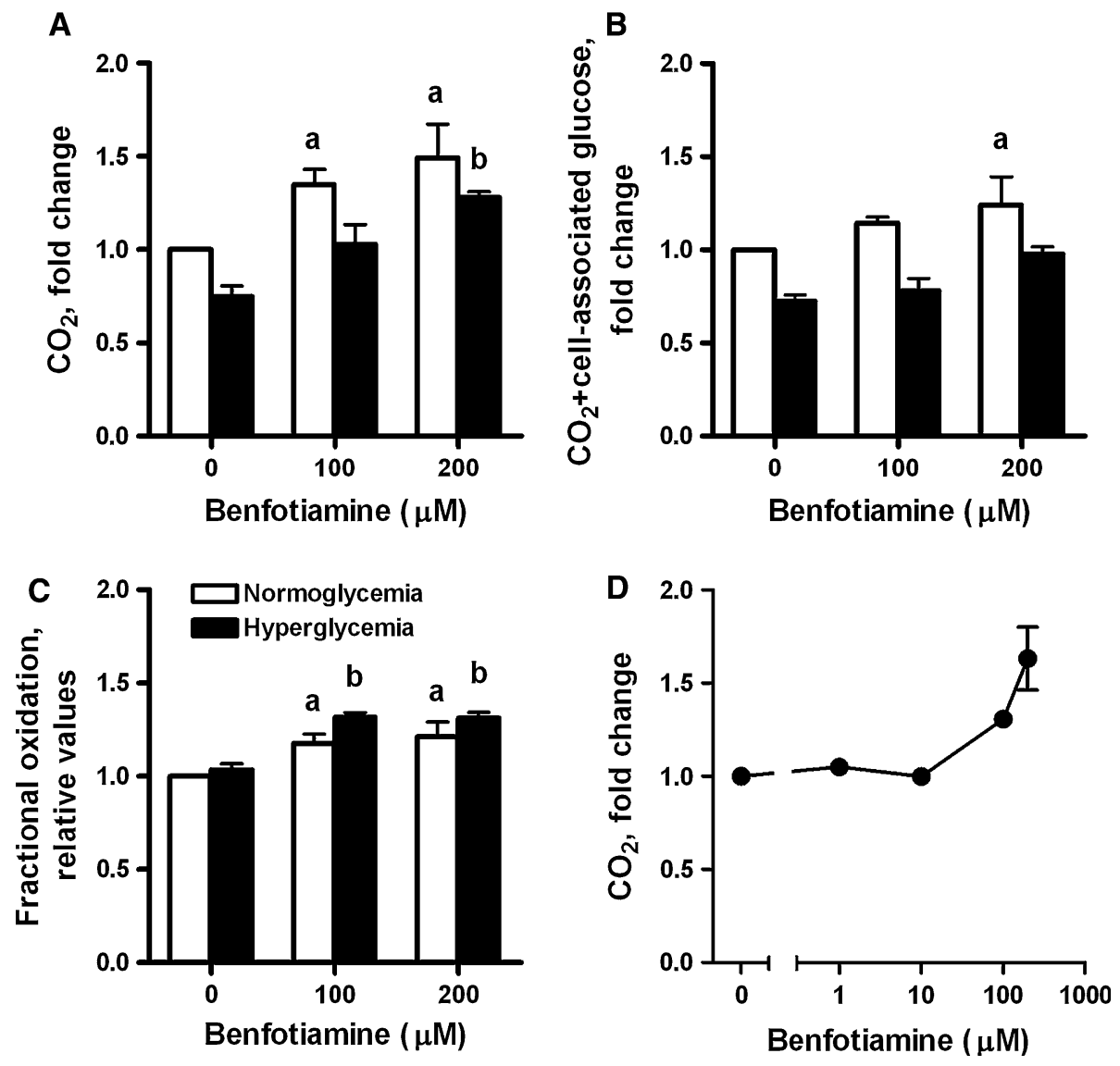

Fig. 1 The effects of benfotiamine on a $\left[\mathrm{U}_{-}{ }^{14} \mathrm{C}\right]$ glucose oxidation ( $\mathrm{CO}_{2}$ formation), b total metabolized glucose (sum of $\mathrm{CO}_{2}$ formation and cell-associated glucose) and $\mathbf{c}$ fractional oxidation of $\left[\mathrm{U}_{-}{ }^{14} \mathrm{C}\right] \mathrm{glu}-$ cose $\left(\mathrm{CO}_{2} /\right.$ sum of cell-associated plus $\left.\mathrm{CO}_{2}\right)$ under NG (normoglycemic, $5.5 \mathrm{mM}$ glucose) and $\mathrm{HG}$ (hyperglycemic, $20 \mathrm{mM}$ glucose) conditions. Myotubes were treated for 4 days in the absence or presence of benfotiamine $(100$ and $200 \mu \mathrm{M})$ under NG and HG conditions. All data are normalized to normoglycemic control and presented as mean $\pm \operatorname{SEM}(n=5$ for $\mathrm{NG}$ and $n=3$ for $\mathrm{HG}$,

on $\left[{ }^{14} \mathrm{C}\right]$ oleic acid $(\mathrm{OA})$ oxidation $\left(\mathrm{CO}_{2}\right.$ formation) and overall lipid utilization $\left(\mathrm{CO}_{2}\right.$ formation plus cell-associated OA) when these processes were studied separately (Fig. 4a, b). However, in contrast to glucose, benfotiamine significantly decreased fractional OA oxidation $\left(\mathrm{CO}_{2} /\right.$ cellassociated $\mathrm{OA}$ plus $\mathrm{CO}_{2}$ ) at both 100 and $200 \mu \mathrm{M}$ benfotiamine under NG conditions as compared with NG alone $(P=0.002$ and 0.007 , respectively, Fig. $4 \mathrm{c})$ and at $200 \mu \mathrm{M}$ benfotiamine under $\mathrm{HG}$ conditions as compared with $\mathrm{HG}$ alone $(P<0.02$, Fig. $4 \mathrm{c})$. HG treatment also decreased fractional oleic acid oxidation (Fig. 4c).

Effects of benfotiamine on gene expression

To examine whether the effects of benfotiamine treatment could be explained by changes in gene expression, microarray analysis was performed. Under normoglycemic

independent muscle cell donors). ${ }^{\mathrm{a}} P<0.05$ versus control myotubes not exposed to benfotiamine under NG conditions; ${ }^{\mathrm{b}} P<0.05$ versus control myotubes not exposed to benfotiamine under HG conditions (linear mixed model (LMM), SPSS). HG treatment significantly decreased glucose oxidation and total metabolized glucose $(P<0.001$ overall effect) (LMM). d Dose-response effects of benfotiamine on $\left[\mathrm{U}_{-}{ }^{14} \mathrm{C}\right]$ glucose oxidation $\left(\mathrm{CO}_{2}\right.$ formation) under NG conditions (mean \pm SEM, $n=2$ )

conditions, a total of more than 100 genes were significantly upregulated after exposure to $200 \mu \mathrm{M}$ benfotiamine, whereas more than 200 genes were downregulated (Tables 1, 2 for the top 20 most down-and upregulated genes; all regulated genes supplementary tables $\mathrm{s} 1$ and $\mathrm{s} 2$ ). NADPH oxidase 4 (NOX4) and growth factor midkine (MDK) were significantly downregulated after benfotiamine treatment $(-2.6$ and $-3.2 \mathrm{FC}$, respectively). Under hyperglycemic conditions, the expression of more than 50 and 100 genes was significantly up- and downregulated after benfotiamine treatment, respectively (Tables 1,2 for the top 20 most down- and upregulated genes, respectively). The expression of NOX4 and MDK was again found to be significantly downregulated by benfotiamine $(-3.1$ and $-3.3 \mathrm{FC}$, respectively). NOX4 expression was verified by qPCR, confirming that benfotiamine had a marked downregulatory effect under both $\mathrm{NG}$ and HG 


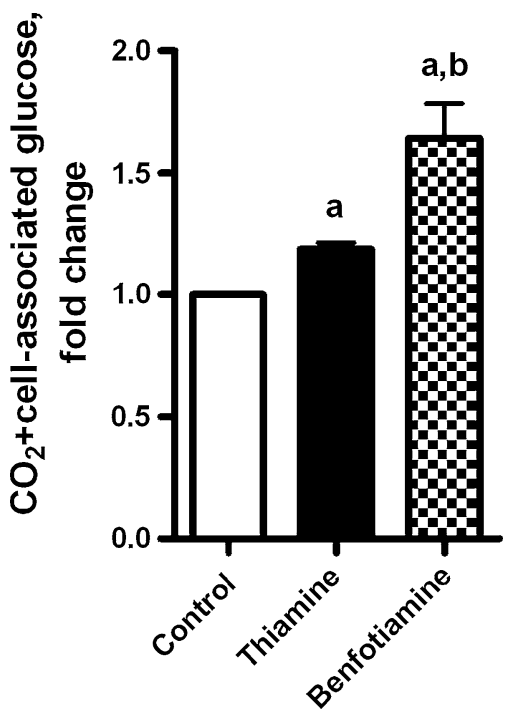

Fig. 2 The effects of thiamine and benfotiamine on total metabolized glucose (sum of $\mathrm{CO}_{2}$ formation and cell-associated glucose). Myotubes were treated for 4 days with or without thiamine $(200 \mu \mathrm{M})$ or benfotiamine $(200 \mu \mathrm{M})$ under NG $(5.5 \mathrm{mM}$ glucose $)$ conditions. All data are normalized to control and presented as mean \pm SEM $(n=3$ independent muscle cell donors). ${ }^{\mathrm{a}} P<0.05$ versus control myotubes not exposed to the compounds; ${ }^{b} P<0.05$ versus thiamine (LMM)

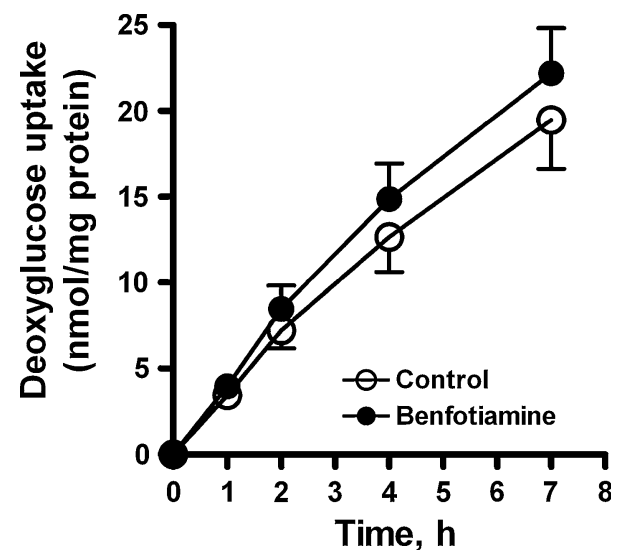

Fig. 3 The effects of benfotiamine on $\left[{ }^{14} \mathrm{C}\right]$ deoxyglucose uptake in cells under NG $(5.5 \mathrm{mM}$ glucose) conditions. Myotubes were treated for 4 days in the absence or presence of benfotiamine $(200 \mu \mathrm{M})$ before the addition of colorless DMEM with $100 \mu \mathrm{M}$ glucose and $\left[{ }^{14} \mathrm{C}\right]$ deoxy-D-glucose $(1 \mu \mathrm{Ci} / \mathrm{ml})$. Data represent mean \pm SEM from cells isolated from 3 individual donors. Benfotiamine significantly increased overall glucose uptake $(P<0.001$, ANOVA repeated measures)

conditions (Fig. 5, $P<0.05$ overall effect). Contrastingly, SERPINB7 (a serine proteinase inhibitor) was significantly upregulated under both normo- and hyperglycemic conditions ( +3.4 and $+2.3 \mathrm{FC}$, respectively). Most of the genes regulated by benfotiamine treatment were regulated both under NG and HG conditions. We did not find any significant changes in the expression of genes encoding for proteins directly involved in lipid or glucose metabolism after benfotiamine treatment.
In addition, we have used GSEA to test the hypothesis that benfotiamine treatment of human myotubes can affect groups of genes associated with glucose metabolism when compared to control cells. A substantial number of relevant gene sets in the defined collections were significantly downregulated after benfotiamine treatment (Table 3). Five gene sets defined by "energy," one gene set defined by "lipid" and two gene sets defined by "transporter" were downregulated after exposure to benfotiamine. We found one upregulated gene set from the "glucose" collection. This gene set was associated with glucuronidation processes. Moreover, 11 gene sets from "lipid" collection were upregulated after benfotiamine treatment. Among these genes sets, there were gene sets involved in peroxisomal fatty acid oxidation and organelle membrane function (including genes important for mitochondrial function). Lists of the differentially regulated gene sets and the genes that contributed to the regulation can be viewed in supplemental table s3.

Microarray data also showed that the level of muscle differentiation markers such as myogenin $(-1.40 \mathrm{FC})$ and myoD ( -1.07 FC) was not significantly affected by benfotiamine, indicating that this treatment does not interfere with the differentiation process of the myotubes.

\section{Discussion}

Our findings are the first to show that benfotiamine increases glucose oxidation $\left(\mathrm{CO}_{2}\right.$ formation) while downregulating NOX4 expression in cultured human myotubes. Benfotiamine also increased overall glucose utilization, which was also shown for thiamine. In contrast to glucose oxidation, we found no significant change in oxidation and overall utilization of oleic acid after incubation with benfotiamine.

Hammes et al. reported that there was no change in TCA cycle activity and that activation of transketolase (TK) was responsible for the effects of benfotiamine on cultured endothelial cells (Hammes et al. 2003). Our contrasting findings suggest that the increase in glucose oxidation that we observed in myotubes does not occur in endothelial cells. Preliminary data in human umbilical vein endothelial cells (HUVEC) support this, as although we observed a marked increase in cell-associated glucose, we did not see the same marked increase in glucose oxidation as we saw in myotubes (data not shown).

It is unclear whether an increase in mitochondrial glucose oxidation, such as we observed, would have an adverse effect on muscle cell function in vivo. In endothelial cells, it has been proposed that the adverse changes observed in endothelial cells exposed to hyperglycemia result from increased glycolytic flux causing an increase in electron donors $\left(\mathrm{NADH}\right.$ and $\left.\mathrm{FADH}_{2}\right)$ to the electron 

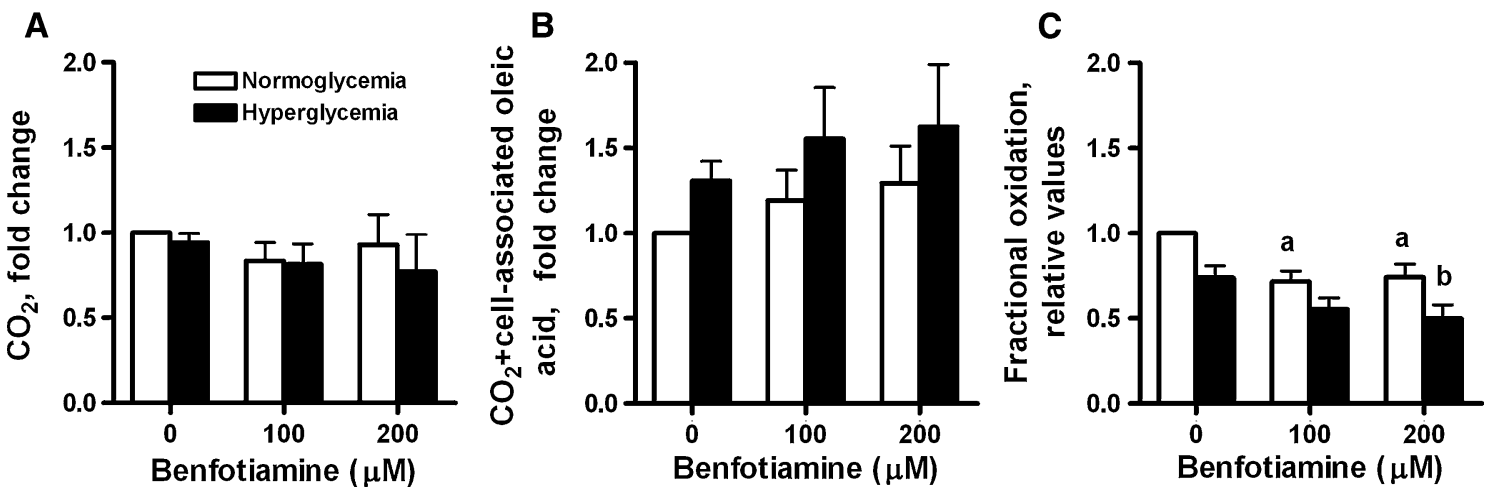

Fig. 4 The effects of benfotiamine on a $\left[1-{ }^{14} \mathrm{C}\right]$ oleic acid (OA) oxidation, $\mathbf{b}$ overall OA utilization (sum of $\mathrm{CO}_{2}$ formation and cellassociated $\mathrm{OA})$ and $\mathbf{c}$ fractional oxidation of $\mathrm{OA}\left(\mathrm{CO}_{2} /\right.$ (sum of cellassociated plus $\left.\mathrm{CO}_{2}\right)$ ) of $\mathrm{OA}$ under $\mathrm{NG}(5.5 \mathrm{mM}$ glucose $)$ and $\mathrm{HG}$ (20 mM glucose) conditions. Myotubes were treated for 4 days with or without benfotiamine $(100$ and $200 \mu \mathrm{M})$ under NG and HG conditions. All data are normalized to normoglycemic control cells and presented as mean $\pm \operatorname{SEM}(n=5$ for NG and $n=6$ for HG, independent muscle cell donors). ${ }^{a} P<0.05$ versus control myotubes not exposed to benfotiamine under NG conditions; ${ }^{\mathrm{b}} P<0.05$ versus control myotubes not exposed to benfotiamine under $\mathrm{HG}$ conditions (LMM). HG treatment significantly decreased fractional oleic acid oxidation $(P<0.01$ overall effect $)(\mathrm{LMM})$

Table 1 Genes downregulated by benfotiamine

\begin{tabular}{|c|c|c|c|c|}
\hline Symbol & Acc & Description & FC NG & $\mathrm{FC} \mathrm{HG}$ \\
\hline LRRN1 & NM_020873 & Leucine rich repeat neuronal 1 & -3.97 & -3.43 \\
\hline RARRES1 & NM_206963 & Retinoic acid receptor responder (tazarotene induced) 1 & -3.62 & -2.50 \\
\hline COMP & NM_000095 & Cartilage oligomeric matrix protein & -3.39 & -4.48 \\
\hline COL15A1 & NM_001855 & Collagen. type XV, alpha 1 & -3.29 & -3.10 \\
\hline SPRR2G & NM_001014291 & Small proline-rich protein $2 \mathrm{G}$ & -3.28 & $-2.85^{*}$ \\
\hline MDK & NM_001012333 & Midkine (neurite growth-promoting factor 2) & -3.23 & -3.34 \\
\hline COL16A1 & NM_001856 & Collagen. type XVI, alpha 1 & -3.18 & -3.05 \\
\hline TYMP & NM_001953 & Thymidine phosphorylase & -2.89 & $-2.20 *$ \\
\hline PACSIN1 & NM_020804 & Protein kinase $\mathrm{C}$ and casein kinase substrate in neurons 1 & -2.89 & -2.30 \\
\hline MYOT & NM_006790 & Myotilin & -2.86 & $-2.40 *$ \\
\hline FAM180B & XM_001716425 & Family with sequence similarity 180 , member B & -2.81 & -3.25 \\
\hline FRAS1 & NM_025074 & Fraser syndrome 1 & -2.75 & -2.88 \\
\hline MGC16121 & XM_001128419 & Hypothetical protein MGC16121 & -2.68 & $-1.45^{*}$ \\
\hline MXRA5 & NM_015419 & Matrix-remodeling associated 5 & -2.67 & -2.72 \\
\hline SORBS2 & NM_021069 & Sorbin and SH3 domain containing 2 & -2.66 & -2.96 \\
\hline HES4 & NM_021170 & Hairy and enhancer of split 4 (Drosophila) & -2.57 & -2.43 \\
\hline NOX4 & NM_016931 & NADPH oxidase 4 & -2.56 & -3.07 \\
\hline CTHRC1 & NM_138455 & Collagen triple helix repeat containing 1 & -2.54 & -1.90 \\
\hline CHN2 & NM_004067 & Chimerin (chimaerin) 2 & -2.53 & $-1.95 *$ \\
\hline CIRBP & NM_001280 & Cold-inducible RNA-binding protein & -2.51 & $-1.94 *$ \\
\hline
\end{tabular}

[20 genes with greatest fold change (FC) decreased after benfotiamine treatment ( $200 \mu \mathrm{M}, 4$ days) as compared to cells not exposed to benfotiamine under NG conditions, with corresponding values under HG conditions], adjusted $P$ value $<0.1$

* Adjusted $P$ value $\geq 0.1 . N=3$ in each group

transport chain and the subsequent generation of superoxide from the mitochondria (Brownlee 2005). However, other studies have indicated that an increase in pyruvate entering the mitochondria is beneficial as this increases the NAD/NADH ratio and thereby reduces the intracellular redox potential (Tilton et al. 1992; Van den Enden et al. 1995). GSEA analysis did not show any effect of benfotiamine on pathways directly involved in glucose metabolism (e.g., glycolysis). However, gene sets involved in peroxisomal lipid oxidation and organelle membrane function (including mitochondrial OXPHOS genes) were upregulated after benfotiamine treatment.

The marked downregulation of NADPH oxidase 4 (NOX4) we observed after incubation with benfotiamine, if 
Table 2 Genes upregulated by benfotiamine

\begin{tabular}{|c|c|c|c|c|}
\hline Symbol & Acc & Description & FC NG & FC HG \\
\hline SERPINB7 & NM_003784 & Serpin peptidase inhibitor, clade B (ovalbumin), member 7 & 3.39 & 2.27 \\
\hline MX1 & NM_002462 & Myxovirus (influenza virus) resistance 1 , interferon-inducible protein p78 (mouse) & 3.19 & $3.32 *$ \\
\hline CPA4 & NM_016352 & Carboxypeptidase A4 & 3.16 & $1.57 *$ \\
\hline TM4SF4 & NM_004617 & Transmembrane $4 \mathrm{~L}$ six family member 4 & 3.11 & $2.14 *$ \\
\hline LCE3D & NM_032563 & Late cornified envelope 3D & 2.76 & 2.54 \\
\hline IFI44L & NM_006820 & Interferon-induced protein 44 -like & 2.62 & 2.54 \\
\hline PSG4 & NM_213633 & Pregnancy specific beta-1-glycoprotein 4 & 2.43 & 1.98 \\
\hline TSGA10 & NM_182911 & Testis specific, 10 & 2.38 & 2.55 \\
\hline NRXN2 & NM_138732 & Neurexin 2 & 2.32 & 1.95 \\
\hline MT1G & NM_005950 & Metallothionein $1 \mathrm{G}$ & 2.32 & 1.44 \\
\hline CCL26 & NM_006072 & Chemokine $(\mathrm{C}-\mathrm{C}$ motif) ligand 26 & 2.18 & $1.60^{*}$ \\
\hline HCG_1815504 & XM_498560 & HCG1815504 & 2.15 & $1.85^{*}$ \\
\hline BRE & NM_199193 & Brain and reproductive organ-expressed (TNFRSF1A modulator) & 2.12 & 1.79 \\
\hline PSG11 & NM_002785 & Pregnancy specific beta-1-glycoprotein 11 & 2.11 & $1.42 *$ \\
\hline TFPI & NM_001032281 & Tissue factor pathway inhibitor (lipoprotein-associated coagulation inhibitor) & 2.10 & $1.40^{*}$ \\
\hline EVI2A & NM_001003927 & Ecotropic viral integration site $2 \mathrm{~A}$ & 2.10 & $1.69 *$ \\
\hline ALDH3A1 & NM_000691 & Aldehyde dehydrogenase 3 family. memberA1 & 2.09 & 2.13 \\
\hline FGGY & NM_001113411 & FGGY carbohydrate kinase domain containing & 2.02 & 1.95 \\
\hline DEFB103B & NM_001081551 & Defensin, beta 103B & 2.01 & $1.27 *$ \\
\hline IFI44 & NM_006417 & Interferon-induced protein 44 & 1.98 & $2.07 *$ \\
\hline
\end{tabular}

[20 genes with greatest fold change (FC) increased after benfotiamine treatment (200 $\mu \mathrm{M}, 4$ days) as compared to cells not exposed to benfotiamine under NG conditions, with corresponding values under $\mathrm{HG}$ conditions], adjusted $P$ value $<0.1$

*Adjusted $P$ value $\geq 0.1$. $N=3$ in each group

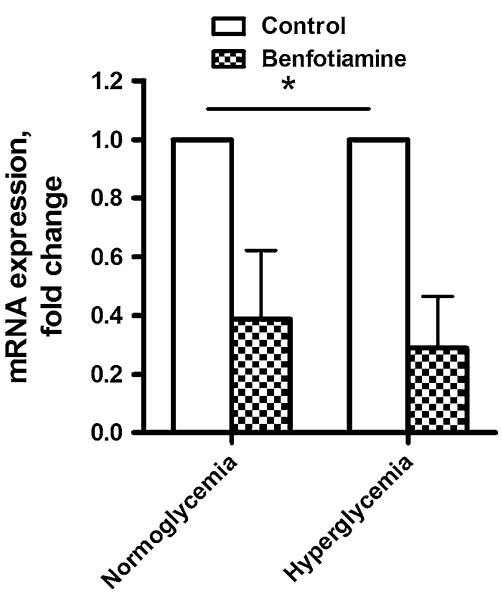

Fig. 5 Effects of benfotiamine on the expression of NADPH oxidase 4 (NOX4) mRNA measured by qPCR. Myotubes were treated for 4 days with or without benfotiamine $(200 \mu \mathrm{M})$ under NG and HG conditions. All data presented as mean $\pm \operatorname{SEM}(n=3$ independent muscle cell donors). $* P<0.05$ overall effect of benfotiamine versus control myotubes (LMM)

also present in other cell types, may be a key mechanism by which this compound exerts its beneficial effects in animal models of diabetes. NOX4 is upregulated in response to hyperglycemia (Xia et al. 2006), is a primary source of reactive oxygen species (Basuroy et al. 2009) and is highly expressed in kidney (Gorin et al. 2005) and vascular endothelial cells (Chen et al. 2008). Benfotiamine has previously been shown to prevent genomic damage to cells exposed to prooxidants in vitro (Schmid et al. 2008) and ex vivo (Schupp et al. 2008). Inhibition of NOX upregulation has been shown to prevent the development of nephropathy in STZ-induced diabetic rat model (Xu et al. 2009). Notably, we found that benfotiamine also downregulated NOX4 expression under normoglycemic conditions, suggesting that benfotiamine may have effects on the constitutive expression of NOX4 unrelated to ambient plasma glucose concentrations. The significant downregulation of growth factor midkine (MDK) we observed after benfotiamine treatment may also exert a beneficial effect since it has been shown to play a key role in the development of diabetic nephropathy in a STZ-induced diabetic mouse model (Kosugi et al. 2006).

Our finding that the serine proteinase inhibitor SERPINB7 was significantly upregulated by benfotiamine under both normo- and hyperglycemic conditions was unexpected. Recent studies have suggested that upregulation of SERPINB7 expression in response to hyperglycemia increases mesangial matrix accumulation and accelerates diabetic nephropathy in mice (Miyata et al. 2002). This may be secondary to inhibition of plasmin and 
Table 3 Number of regulated gene sets comparing control and benfotiamine treatment within each group under normoglycemic (NG) conditions (paired GSEA analysis, score: log-fold change, $\mathrm{FDR} \leq 5 \%)$

\begin{tabular}{lcll}
\hline $\begin{array}{l}\text { Gene set } \\
\text { collections }\end{array}$ & $\begin{array}{l}\text { Number } \\
\text { of gene } \\
\text { sets in } \\
\text { collection }\end{array}$ & $\begin{array}{l}\text { Control }> \\
\text { benfotiamine } \\
\text { (downregulated } \\
\text { by treatment) }\end{array}$ & $\begin{array}{l}\text { Benfotiamine }> \\
\text { control } \\
\text { (upregulated } \\
\text { by treatment) }\end{array}$ \\
\hline C5 bp & 753 & 1 & 0 \\
C3TFT & 582 & 5 & 0 \\
C2 & 846 & 2 & 7 \\
Energy & 63 & 5 & 1 \\
Glucose & 63 & 0 & 1 \\
Insulin & 97 & 0 & 0 \\
Lipid & 141 & 1 & 11 \\
DNA and repair & 77 & 0 & 0 \\
Interleukin & 133 & 1 & 0 \\
Lactate & 5 & 0 & 0 \\
Mitochondria & 29 & 0 & 0 \\
Transporter & 29 & 2 & 0
\end{tabular}

A gene set browser provided by Broad institute at http://www. broad.mit.edu/gsea/was used to obtain the stress-associated gene set collections. Detailed information regarding the regulated gene sets and leading edge genes is given in online supplementary table s3

a Indicates that truncated search keyword was used to create the gene set collections. C2, C3TFT and C5 are predefined gene set collections. $N=3$ in each group

matrix metalloproteinase activity (Ohtomo et al. 2008). This finding does not concord with a previous study, showing that benfotiamine actually protects against diabetic nephropathy in animal models (Babaei-Jadidi et al. 2003). The reasons for this discrepancy are unclear but may be related to differences in myotubes as compared to mesangial cells where SERPINB7 is predominantly expressed.

In addition to increasing TK activity, it has previously been found that benfotiamine increases the expression of TK in renal glomeruli (Loew 1996). However, we did not find any change in the gene expression of TK in human myotubes using microarray. In addition, we did not find any significant changes in genes encoding enzymes involved in glycolysis and/or the TCA cycle that might suggest that the increased oxidation we observed may be secondary to changes in enzyme activity rather than gene expression levels.

Using benfotiamine, in vitro differs from in vivo since most of the benfotiamine given orally is partially dephosporylated in the gut to benzoylthiamine. Due to the enhanced membrane permeability of benzoylthiamine, oral benfotiamine leads to higher plasma and intracellular concentrations of the active metabolite, thiamine diphosphate (TPP), than thiamine (Loew 1996). Although intact benfotiamine is also delivered to cells via the reduced folate carrier-1 (RFC-1) which is then de-benzoylated to thiamine monophosphate (TMP) by cellular and plasma esterases (Thornalley and Babaei-Jadidi 2005), it is not superior to thiamine in increasing the intracellular concentrations of thiamine in vitro (Volvert et al. 2008). The exposure of cells in vivo to intact benfotiamine is minimal (peak plasma concentration approx. $10 \mathrm{nM}$ in subjects taking $250 \mathrm{mg}$ benfotiamine/day) as compared to the supra-pharmacological concentrations used in this study (100-200 $\mu \mathrm{M}$; Ziems et al. 2000). Although doses as high as $900 \mathrm{mg}$ benfotiamine per day have been used clinically (Alkhalaf et al. 2010), we must take into account the possibility that the effects we observed were associated with the high concentrations used, which might result in the generation of esterase-derived thiols at concentrations not observed in vivo. It is also possible that benfotiamine, but not thiamine, induces spontaneous rearrangement of $\mathrm{S}$-acylcysteine derivatives to $\mathrm{N}$-acylcysteine derivatives that affects pyrimidine synthesis and related signaling (Edwards et al. 1996).

Interestingly, we also found an increase in glucose oxidation in cells exposed to normoglycemia in the presence of benfotiamine. The effects we observed are therefore not simply a result of benfotiamine abolishing the previously documented inhibitory effects of hyperglycemia on glucose uptake in myotubes (Aas et al. 2004). However, we also found that $200 \mu \mathrm{M}$ benfotiamine was able to reverse the inhibitory effect of hyperglycemia on glucose oxidation. We have previously shown that chronic hyperglycemia reduces insulin-stimulated glucose uptake and increases triacylglycerol formation from labeled glucose (Aas et al. 2004). We assessed the effects of benfotiamine on overall glucose uptake under normoglycemic conditions both with and without insulin and only found a small (17\%) but significant increase in benfotiamine. Although we cannot say whether this increased uptake preceded or was a result of the increase in glucose oxidation, this increase in uptake was relatively minor compared with the more pronounced increase in glucose oxidation (35-70\%). This would suggest that the effects of benfotiamine on glucose oxidation cannot be explained by an increased glucose uptake itself.

The decrease we noted in fractional oleic acid oxidation may reflect the inverse reciprocal relationship between glucose and lipid oxidation. This finding also makes it unlikely that the increase we observed in glucose oxidation is a result of a benfotiamine-induced change in myotube differentiation. Additionally, we found no changes in muscle differentiation markers such as myogenin and myoD. However, our finding that benfotiamine decreased fractional oleic acid oxidation while increasing fractional glucose oxidation suggests that benfotiamine may 
stimulate a preferential oxidation of glucose at the expense of fatty acids. This may be secondary to increased generation of pyruvate from glycolysis. GSEA analysis also suggested that fatty acids could be channeled to peroxisomes for oxidation after treatment with benfotiamine.

Most previous research into the biochemical effects of benfotiamine has focused on cells, such as endothelial cells, susceptible to hyperglycemic-associated damage (Balakumar et al. 2010). The clinical implications of the results from the present study are that oral benfotiamine has marked metabolic effects on cells i.e., skeletal muscle, other than those typically associated with diabetic microvascular complications. Whether our results can be extrapolated to the in vivo situation is not clear, as the marked effects we observed were achieved using supraphysiologic concentrations of benfotiamine. If such effects do occur in vivo, our results suggest that benfotiamine may not only be beneficial for microvascular complications associated with type 1 diabetes but could also be of relevance to type 2 diabetes and obesity where reversal of reduced mitochondrial capacity and decreased glucose oxidation is a desirable goal (Aas et al. 2011).

In conclusion, our study has shown that benfotiamine, but not thiamine, causes a marked increase in mitochondrial glucose oxidation in human skeletal muscle cells. Our finding that benfotiamine also reduces NOX4 gene expression offers a new insight into the mechanism/s by which this substance exerts its effects on the development of diabetic complications. These findings suggest that benfotiamine has a wider range of effects in different cell types of relevance to both type 1 and type 2 diabetes than has previously been recognized.

\section{References}

Aas V, Kase ET, Solberg R, Jensen J, Rustan AC (2004) Chronic hyperglycaemia promotes lipogenesis and triacylglycerol accumulation in human skeletal muscle cells. Diabetologia 47(8):1452-1461

Aas V, Hessvik NP, Wettergreen M, Hvammen AW, Hallen S, Thoresen GH, Rustan A (2011) Chronic hyperglycemia reduces substrate oxidation and impairs metabolic switching of human myotubes. Biochim Biophys Acta Mol Basis Dis 1812:94-105

Alkhalaf A, Klooster A, van Oeveren W, Achenbach U, Kleefstra N, Slingerland RJ, Mijnhout GS, Bilo HJ, Gans RO, Navis GJ, Bakker SJ (2010) A double-blind, randomized, placebo-controlled clinical trial on benfotiamine treatment in patients with diabetic nephropathy. Diabetes Care 33(7):1598-1601

Babaei-Jadidi R, Karachalias N, Ahmed N, Battah S, Thornalley PJ (2003) Prevention of incipient diabetic nephropathy by highdose thiamine and benfotiamine. Diabetes 52(8):2110-2120

Balakumar P, Rohilla A, Krishan P, Solairaj P, Thangathirupathi A (2010) The multifaceted therapeutic potential of benfotiamine. Pharmacol Res 61(6):482-488
Basuroy S, Bhattacharya S, Leffler CW, Parfenova H (2009) Nox4 NADPH oxidase mediates oxidative stress and apoptosis caused by TNF-alpha in cerebral vascular endothelial cells. Am J Phys Cell Physiol 296(3):C422-C432

Benjamini Y, Hochberg Y (1995) Controlling the false discovery rate: a practical and powerful approach to multiple testing. J R Statist Soc B 57(1):289-300

Bohn SK, Myhrstad MC, Thoresen M, Holden M, Karlsen A, Tunheim SH, Erlund I, Svendsen M, Seljeflot I, Moskaug JO, Duttaroy AK, Laake P, Arnesen H, Tonstad S, Collins A, Drevon CA, Blomhoff R (2010) Blood cell gene expression associated with cellular stress defense is modulated by antioxidant-rich food in a randomised controlled clinical trial of male smokers. BMC Med 8:54

Bradford MM (1976) A rapid and sensitive method for quantitation of microgram quantities of protein utilizing the principle of proteindye binding. Anal Biochem 72:248-254

Brazma A, Hingamp P, Quackenbush J et al (2001) Minimum information about a microarray experiment (MIAME)-toward standards for microarray data. Nat Genet 29(4):365-371

Brinchmann-Hansen O, Dahl-Jorgensen K, Sandvik L, Hanssen KF (1992) Blood glucose concentrations and progression of diabetic retinopathy: the seven year results of the Oslo study. BMJ 304(6818):19-22

Brownlee M (2001) Biochemistry and molecular cell biology of diabetic complications. Nature 414(6865):813-820

Brownlee M (2005) The pathobiology of diabetic complications: a unifying mechanism. Diabetes 54(6):1615-1625

Chen K, Kirber MT, Xiao H, Yang Y, Keaney JF Jr (2008) Regulation of ROS signal transduction by NADPH oxidase 4 localization. J Cell Biol 181(7):1129-1139

Edwards LG, Adesida A, Thornalley PJ (1996) Inhibition of human leukaemia 60 cell growth by S-D-lactoylglutathione in vitro. Mediation by metabolism to N-D-lactoylcysteine and induction of apoptosis. Leukemia Res 20(1):17-26

Gorin Y, Block K, Hernandez J, Bhandari B, Wagner B, Barnes JL, Abboud HE (2005) Nox4 NAD(P)H oxidase mediates hypertrophy and fibronectin expression in the diabetic kidney. J Biol Chem 280(47):39616-39626

Hammes HP, Du X, Edelstein D, Taguchi T, Matsumura T, Ju Q, Lin J, Bierhaus A, Nawroth P, Hannak D, Neumaier M, Bergfeld R, Giardino I, Brownlee M (2003) Benfotiamine blocks three major pathways of hyperglycemic damage and prevents experimental diabetic retinopathy. Nat Med 9(3):294-299

Hilbig R, Rahmann H (1998) Comparative autoradiographic investigations on the tissue distribution of benfotiamine versus thiamine in mice. Arzneimittelforschung 48(5):461-468

Kosugi T, Yuzawa Y, Sato W, Kawai H, Matsuo S, Takei Y, Muramatsu T, Kadomatsu K (2006) Growth factor midkine is involved in the pathogenesis of diabetic nephropathy. Am J Pathol 168(1):9-19

Loew D (1996) Pharmacokinetics of thiamine derivatives especially of benfotiamine. Int J Clin Pharmacol Ther 34(2):47-50

Miyata T, Inagi R, Nangaku M, Imasawa T, Sato M, Izuhara Y, Suzuki D, Yoshino A, Onogi H, Kimura M, Sugiyama S, Kurokawa K (2002) Overexpression of the serpin megsin induces progressive mesangial cell proliferation and expansion. J Clin Invest 109(5):585-593

Ohtomo S, Nangaku M, Izuhara Y, Yamada N, Dan T, Mori T, Ito S, de Strihou C, Miyata T (2008) The role of megsin, a serine protease inhibitor, in diabetic mesangial matrix accumulation. Kidney Int 74(6):768-774

Pagel-Langenickel I, Bao J, Pang L, Sack MN (2010) The role of mitochondria in the pathophysiology of skeletal muscle insulin resistance. Endocrine Rev 31(1):25-51

Richter EA, Hansen BF, Hansen SA (1988) Glucose-induced insulin resistance of skeletal-muscle glucose transport and uptake. Biochem J 252(3):733-737 
Sartor MA, Tomlinson CR, Wesselkamper SC, Sivaganesan S, Leikauf GD, Medvedovic M (2006) Intensity-based hierarchical Bayes method improves testing for differentially expressed genes in microarray experiments. BMC Bioinformatics 7:538

Schmid U, Stopper H, Heidland A, Schupp N (2008) Benfotiamine exhibits direct antioxidative capacity and prevents induction of DNA damage in vitro. Diabetes Metab Res Rev 24(5):371-377

Schupp N, Dette EM, Schmid U, Bahner U, Winkler M, Heidland A, Stopper H (2008) Benfotiamine reduces genomic damage in peripheral lymphocytes of hemodialysis patients. Naunyn Schmiedebergs Arch Pharmacol 378(3):283-291

Subramanian A, Tamayo P, Mootha VK, Mukherjee S, Ebert BL, Gillette MA, Paulovich A, Pomeroy SL, Golub TR, Lander ES, Mesirov JP (2005) Gene set enrichment analysis: a knowledgebased approach for interpreting genome-wide expression profiles. Proc Natl Acad Sci 102(43):15545-15550

The Diabetes Control and Complications Trial Research Group (1993) The effect of intensive treatment of diabetes on the development and progression of long-term complications in insulin-dependent diabetes mellitus. N Engl J Med 329(14):977-986

Thornalley PJ, Babaei-Jadidi R (2005) Prevention of microvascular complications of diabetes by high dose S-benzoylthiamine monophosphate (Benfotiamine): mechanism of thiamine delivery into cells. Diabetologia 48:(Suppl 1)

Tilton RG, Baier LD, Harlow JE, Smith SR, Ostrow E, Williamson JR (1992) Diabetes-induced glomerular dysfunction: links to a more reduced cytosolic ratio of NADH/NAD+. Kidney Int 41(4): 778-788
UK Prospective Diabetes Study (UKPDS) Group (1998) Intensive blood-glucose control with sulphonylureas or insulin compared with conventional treatment and risk of complications in patients with type 2 diabetes (UKPDS 33). Lancet 352(9131):837-853

Van den Enden MK, Nyengaard JR, Ostrow E, Burgan JH, Williamson JR (1995) Elevated glucose levels increase retinal glycolysis and sorbitol pathway metabolism. Implications for diabetic retinopathy. Invest Ophth Vis Sci 36(8):1675-1685

Volvert ML, Seyen S, Piette M, Evrard B, Gangolf M, Plumier JC, Bettendorff L (2008) Benfotiamine, a synthetic S-acyl thiamine derivative, has different mechanisms of action and a different pharmacological profile than lipid-soluble thiamine disulfide derivatives. BMC Pharmacol 8:10

Wensaas AJ, Rustan AC, Lovstedt K, Kull B, Wikstrom S, Drevon CA, Hallen S (2007) Cell-based multiwell assays for the detection of substrate accumulation and oxidation. J Lipid Res 48(4):961-967

Xia L, Wang H, Goldberg HJ, Munk S, Fantus IG, Whiteside CI (2006) Mesangial cell NADPH oxidase upregulation in high glucose is protein kinase $\mathrm{C}$ dependent and required for collagen IV expression. Am J Physiol Renal Physiol 290(2):F345-F356

Xu M, Dai DZ, Dai Y (2009) Normalizing NADPH oxidase contributes to attenuating diabetic nephropathy by the dual endothelin receptor antagonist CPU0213 in rats. Am J Nephrol 29(3):252-256

Ziems M, Netzel M, Bitsch I (2000) Biokinetic parameters and metabolism of S-benzoylthiamine-O-monophosphate. Biofactors 11(1-2):109-110 